\section{ADVANCED ENERGY MATERIALS}

Postfach 101161 69451 Weinheim Germany Courier services:

Boschstraße 12 69469 Weinheim Germany

Dear Author,

Please correct your galley proofs carefully and return them no more than four days after the page proofs have been received.

Please limit corrections to errors already in the text; cost incurred for any further changes or additions will be charged to the author, unless such changes have been agreed upon by the editor.

The editors reserve the right to publish your article without your corrections if the proofs do not arrive in time.

Note that the author is liable for damages arising from incorrect statements, including misprints.

Please note any queries that require your attention. These are indicated with a $Q$ in the PDF and a question at the end of the document.

Reprints may be ordered by filling out the accompanying form.

Return the reprint order form by fax or by e-mail with the corrected proofs, to WileyVCH : advenergymat@wiley.com
To avoid commonly occurring errors, please ensure that the following important items are correct in your proofs (please note that once your article is published online, no further corrections can be made):

- Names of all authors present and spelled correctly

- Titles of authors correct (Prof. or Dr. only: please note, Prof. Dr. is not used in the journals)

- Addresses and postcodes correct

- E-mail address of corresponding author correct (current email address)

- Funding bodies included and grant numbers accurate

- Title of article OK

- All figures included

- Equations correct (symbols and sub/superscripts)

Corrections should be made directly in the PDF file using the PDF annotation tools. If you have questions about this, please contact the editorial office. The corrected PDF and any accompanying files should be uploaded to the journal's Editorial Manager site. 


\section{FULL PAPERS}

Q1 $\begin{array}{lll}1 & 2 & \times 2\end{array}$

R. R. Bahabry, A. T. Kutbee, S. Khan, A. C. Sepulveda, I. Wicaksono, M. Nour, N. Wehbe, A. S. Almislem, M. T. Ghoneim, G. A. Torres Sevilla, A. Syed, S. F. Shaikh, M. M. Hussain* 1702221

Corrugation Architecture Enabled Ultraflexible Wafer-Scale HighEfficiency Monocrystalline Silicon Solar Cell

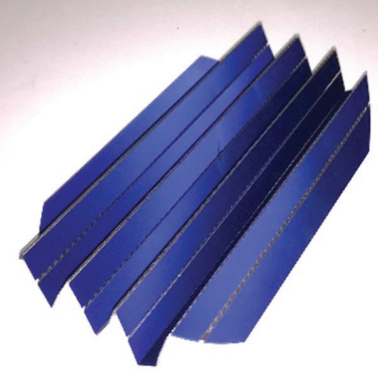

A corrugation architecture enabled ul- 1 traflexible, high performance crystalline-silicon solar cells on a 5 inch wafer 4 via a lithography less complementary 5 metal oxide semiconductor compatible 6 technique shows power conversion effi- 7 ciency of $17.2 \%$, a bending radius lower 8 than $140 \mu \mathrm{m}$ with the groove width of 8 $0.86 \mathrm{~mm}$, and a high mechanical stability 10 over 1000 cyclic bending. 


\title{
Corrugation Architecture Enabled Ultraflexible Wafer-Scale High-Efficiency Monocrystalline Silicon Solar Cell
}

\author{
Rabab R. Bahabry, Arwa T. Kutbee, Sherjee Dhan, Adrian C. Sepulveda, Irmandy Wicaksono, \\ Maha Nour, Nimer Wehbe, Amani S. Almislem, Mohamed T. Ghoneim, \\ Galo A. Torres Sevilla, Ahad Syed, Sohail F. Shaikh, and Muhammad M. Hussain*
}

Advanced classes of modern application require new generation of versatile solar cells showcasing extreme mechanical resilience, large-scale, low cost, and excellent power conversion efficiency. Conventional crystalline siliconbased solar cell offers one of the most highly efficient power sources, but a key challenge remains to attain its mechanical resilience while preserving electrical performance. A complementary metal oxide semiconductor- based integration strategy where corrugation architecture enables an ultraflexible and low-cost solar cell modules from bulk monocrystalline large-scale $\left(127 \times 127 \mathrm{~cm}^{2}\right)$ silicon solar wafer with $17 \%$ power conversion efficiency. This periodic corrugated array benefit from an interchangeable solar cell segmentation scheme which preserves the active silicon thickness of $240 \mu \mathrm{m}$ and achieves flexibility via an interdigitated back contacts. These cells can reversibly withstand high mechanical stress and can be deformed to zigzag and bifacial modules. Theses corrugation silicon-based solar cells offer ultraflexibility with high stability over 1000 bending cycles including convex and concave bending to broaden the application spectrum. Finally, the smallest bending radius of curvature lower than $140 \mu \mathrm{m}$ of the back contacts is shown that carries the solar cells segments.

\section{Introduction}

Flexible solar cell technology has paved the way for wide application spectrum ranging from wearable and implantable electronics, robotics, and infrastructure/vehicle-integrated solar

R. R. Bahabry, A. T. Kutbee, A. C. Sepulveda

Integrated Nanotechnology Lab and Integrated Disruptive Electronic Applications (IDEA) Lab

Material Science and Engineering

Physical Science and Engineering Division

King Abdullah University of Science and Technology (KAUST)

Thunal 23955-6900, Saudi Arabia

S. k2 h. Nour, A. S. Almislem SThoneim,

T. Torres Sevilla, S. F. Shaikh, Hussain

2 rated Nanotechnology Lab 2. ntegrated Disruptive

Electronic Applications (IDEA) Lab

Electrical Engineering

Computer Electrical and Mathematical Sciences and Engineering Division

King Abdullah University of Science and Technology (KAUST)

Thuwal 23955-6900, Saudi Arabia

E-mail: muhammadmustafa.hussain@kaust.edu.sa

The ORCID identification number(s) for the author(s) of this article can be found under https://doi.org/10.1002/aenm.201702221.

DOI: 10.1002/aenm.201702221 ciencies as compared to polycrystalline compounds or organic 37 solar cells, due to high material quality. ${ }^{[12,13]}$

In this regard, two main approaches are explored extensively for producing TFSCs. The first approach includes direct deposition of the TFSCs on flexible substrate, such as polymers,

I. Wicaksono

Department of Electrical Engineering and Information Technology 44

Swiss Federal Institute of Technology (ETH) Zurich

Rämistrasse 101, Zürich 8092, Switzerland

E. Dehbe

2 ing and Characterization Lab Core Facilities

King Abdullah University of Science and Technology (KAUST)

Thuwal 23955-6900, Saudi Arabia

A. Syed

Nanofabrication Core Lab

King Abdullah University of Science and Technology (KAUST)

Thuwal 23955-6900, Saudi Arabia 
1 fabrics, and paper. ${ }^{[14,15]}$ Such method is restricted by the max2 imum temperature of the substrate materials, impacting the 3 solar cells performance. ${ }^{[12]}$ The second approach is the transfer 4 printing technique which utilizes the conventional rigid sub5 strates for the fabrication and then transfer the TFSCs onto 6 resilient substrate. ${ }^{[16,17]}$ Thus, the second method overcomes 7 the performance limitation associated with the substrate 8 thermal incompatibility with fabrication of high-efficiency 9 TFSCs. However, it suffers from both of low throughput and 10 high cost. Thus, a trade-off between mechanical compliance, 11 performance, and robustness of flexible photovoltaic cells 12 remains as a major challenge, especially in high volume pro13 duction for large surface coverage applications.

14 Here, we show a novel approach for flexing crystalline 15 (c-Si) solar cells which overcome the previous major limita16 tions associated with the material thickness reduction and the 17 high cost of flexing process. Our approach is inspired by the 18 corrugated architecture where thin areas are grooved between 19 thicker areas which eventually makes the platform in-hand flex20 ible. We have grooved series of linear channels $(\approx 1 \mathrm{~mm}$ wide) 21 without photolithography to reduce the thickness of silicon in 22 those areas while keeping the remaining areas intact in silicon 23 solar cell $(\approx 6.2 \mathrm{~mm}$ wide). This corrugated architecture silicon 24 solar cells show extreme bending radius $<140 \mu \mathrm{m}$ of the back 25 contacts with one of the highest power conversion efficiency 26 among c-Si flexible solar cells that reaches $17.2 \%$ on a wafer 27 scale $(127 \times 127 \mathrm{~mm})$. We also demonstrate high mechanical 28 stability of the cells during 1000 cycles of bending. Finally, 29 the integration of the flexible solar cells is demonstrated on 30 a curved surface for supplying power both flexible $8 \times 8$ LED 31 Matrix and paper-based fully functional system using indoor 32 illumination.

\section{Results and Discussion}

\subsection{Ultraflexible c-Si Solar Cell}

The mechanical adaptability of the corrugated c-Si solar cells concept is illustrated in Figure 1. We have used interdigitated back contact (IBC) solar cells with an area of $127 \times 127 \mathrm{~mm}^{2}$. Each wafer comprises an interdigitated $\mathrm{p}$ and $\mathrm{n}$ regions on a bulk silicon wafer with $\approx 260 \mu \mathrm{m}$ thickness as depicted in Figure S1 (Supporting Information). ${ }^{[18]}$ The IBC solar cell modules are highly attractive due to their high efficiency and advanced photons absorption attributed to less contact shading compared to the standard front-side contacts modules. Additionally, the IBC configuration simplifies our flexing process without the utilization of expensive lithography techniques where the silicon thinning process is executed on the whole front side without any precautions needed for handling the contacts. In order to achieve extreme flexibility, corrugation architecture or segmentation was utilized on the IBC wafers with an alternating regions of thinned and rigid Si discontinuities as shown in Figure 1a,b and Figure S2 (Supporting Information). The optical image of the corrugated c-Si solar cell is shown in Figure 1c demonstrating extreme mechanical bending flexibility. It cannot only be bent but also can be deformed into different configurations including a zigzag and bifacial modules as shown in Figure 1e,f, respectively. An optical front view 1 image of the zigzag configuration depicted in Figure $1 \mathrm{~g}$ in 2 which an extraordinary flexibility and plastic deformation of 3 the interdigitated back contact with the acute bending angle of 4 $71.4^{\circ}$ as observed using scanning electron microscopy imaging 5 (SEM) (Figure 1h). Further SEM imaging of the top view of the 6 sample is revealed in Figure 1i showing both of the negative 7 and positive IBC electrodes with a width of 0.42 and $1.6 \mathrm{~mm}$, respectively. Figure 1J demonstrates the extreme bending flexibility of the back contacts which carries the solar cells segments that can be folded around a radius $<140 \mu \mathrm{m}$. Moreover, the microstructure of the active solar cell and the bent contact is shown in Figure $1 \mathrm{k}$ with no presence of microcracks in the contact region.

In order to facilitate the industrial c-Si solar cells with the flexible version of the modules and a comparable efficiency, our corrugated flexing technique is designed to be applied on 5" wafer size with a lithography less approach. The main flexing steps are depicted in Figure 2a (see Experimental Section for details). The combination of the photoresist (PR) and the Kapton tape which has been applied manually work as a hard mask against the plasma etching. Moreover, the PR layer enables smooth peel-off of the Kapton with no residues on the active solar area after the flexing process is completed. To assess the plasma etching effect of the silicon etching progression and the underlying IBC surface, cross-section SEM imaging, Zygo profiler measurements, for IBC surface roughness, and secondary ion mass spectrometry (SIMS) spectra analysis, were carried out. Figure $2 \mathrm{~b}$ shows the optical photo of the wafer after the plasma etching is completed. Figure $2 \mathrm{c}$ presents the optical microscopy image of upper side of the IBC contacts with the root mean square average of $1.269 \mu \mathrm{m}$. The silicon thickness reduces during the deep reactive ion etching (DRIE) process from $240 \mu \mathrm{m}$ at the start, to $170 \mu \mathrm{m}$ at 250th cycle $(54 \mathrm{~min}$ ), to $71 \mu \mathrm{m}$ at 450 th cycle $(99 \mathrm{~min})$, and finally the silicon is etched totally at 650th cycle. Thickness reduction against DRIE etching cycles along with consumed etching time is plotted in Figure 2e. In addition, SEM images are carried out in Figure 2f,g after 54 and 99 min of DRIE etching, respectively. In order to verify the silicon etching process, the etched grooves were analyzed using SIMS in both positive and negative modes. In Figure $2 \mathrm{~h}$, the analyzed film is composed mainly of aluminum, in addition to alkali and alkaline earth $(\mathrm{Na}, \mathrm{K}$, and $\mathrm{Ca}$ ) and halogen metals (F) commonly detected as contaminant in SIMS. The positive and negative spectra are complementary since the most intense peak in the positive mode is $\mathrm{Al}^{+}$(mass 27), whereas $\mathrm{AlO}^{-}$(mass 43) is the most intense peak in the negative mode. Although the aluminum film is expected to oxidize after contact with air, the intense aluminum oxide signals detected in both modes are also due to the usage of oxygen as a sputtering beam.

\subsection{Solar Cell Efficiency}

The current density-voltage $(J-V)$ characteristics are measured under a solar simulator (approximately the AM 1.5 Global Spectrum with $100 \mathrm{~mW} \mathrm{~cm}{ }^{-2}$ intensity and spectral mismatch correction at the room temperature), and in the dark using a four-point probe setup to reduce the resistance associated , ? 
a

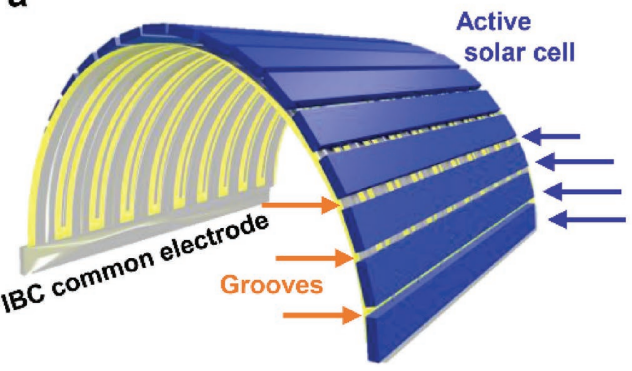

b

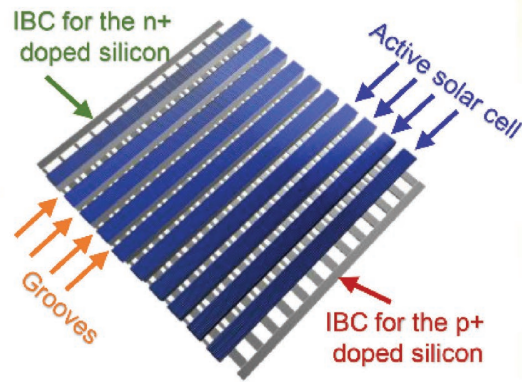

c

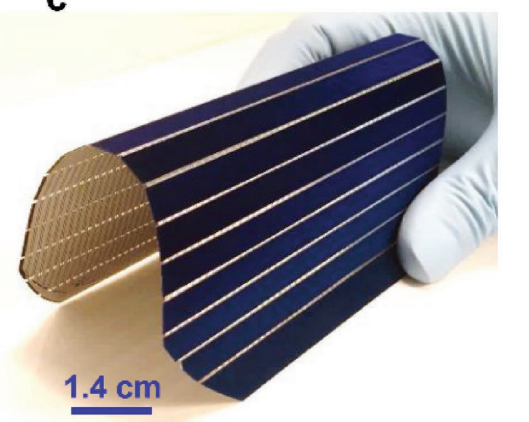

2

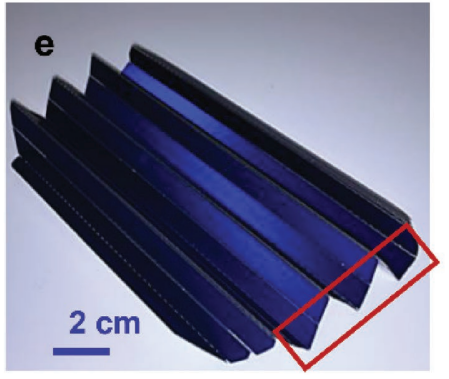

Ultra flexible

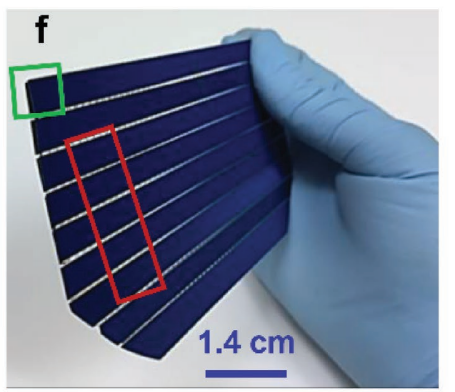

d

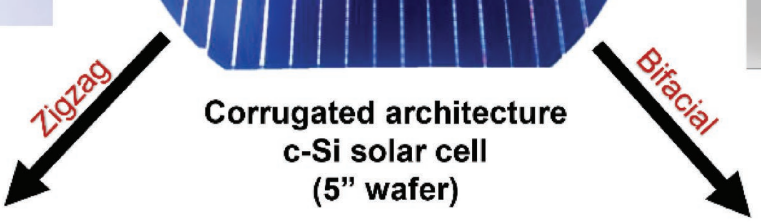

19

20

21

22

23
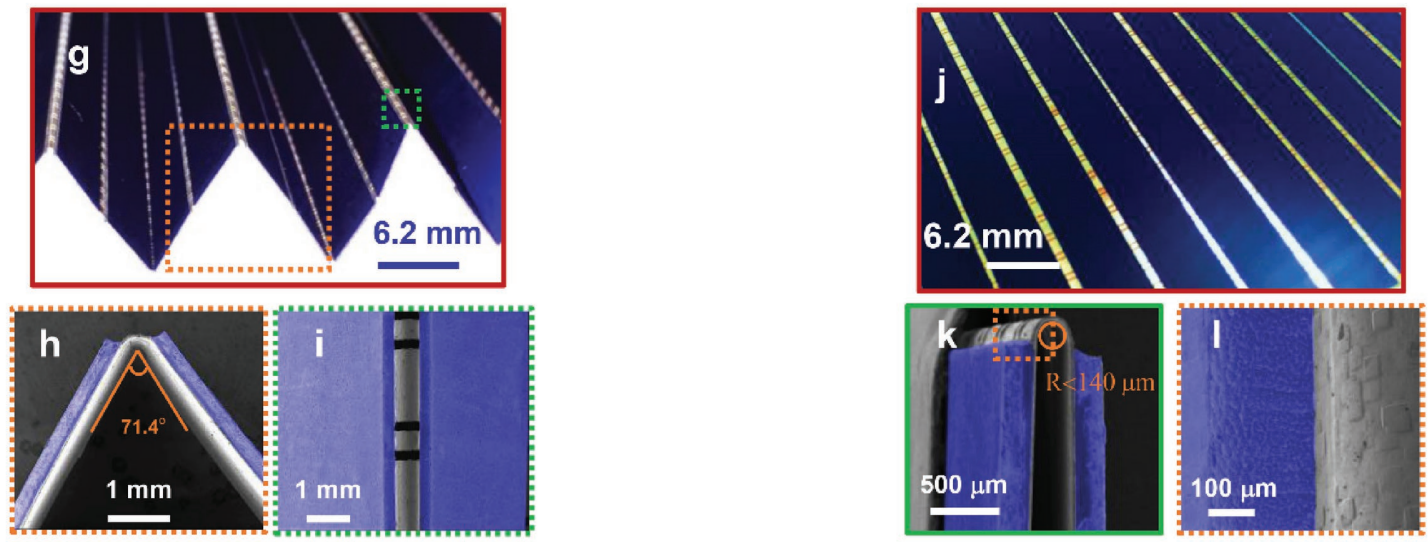

41

Figure 1. Ultraflexible c-Si solar cells on a 5 inch wafer scale. Schematic representation of a) the ultraflexible corrugated c-Si solar cell. b) The common 48 electrodes of the interdigitated back contact corrugated c-Si solar cell. Optical images of $5^{\prime \prime}$ wafer of c-Si IBC solar cell illustrates: c) high bending 49 flexibility, d) flat, e) zigzag module, f) folded wafer in half to obtain bifacial demonstration, and g) the zigzag side view and the internal angle $(\theta)$. 50 Scanning electron microscopy images: h) Cross-sectional shows zigzag deformation with $\theta=71.4^{\circ}$ and i) top view reveals the deformation of the 51 interdigitated contacts. j) Optical image illustrates the view of the corrugated architecture consists of $\approx 6.2 \mathrm{~mm}$ active solar cell segments and $0.8 \mathrm{~mm} 52$ grooves width. SEM images of: $\mathrm{k}$ ) the minimum bending radii of curvature of the back contacts $(R=<140$ um $)$ during folding, and I) pop view of the 53 folded aluminum contact and the silicon segments.

with the high current collected from $15 \times 127 \mathrm{~mm}^{2} \mathrm{c}$-Si solar cell. The measured cells were diced using laser with power of $100 \%$, speed of $60 \%$, and $500 \mathrm{kHz}$ (see Figure S3, Supporting Information for laser optimization). For each cell, the reported figures of merit for calculating each of the current density 56 $(J)$, power density $(P)$, and power conversion efficiency $(\eta) 57$ are based on active solar cells area only excluding the area of 58 grooves where no photocurrent is generated which was found 59 
1

2

3 a
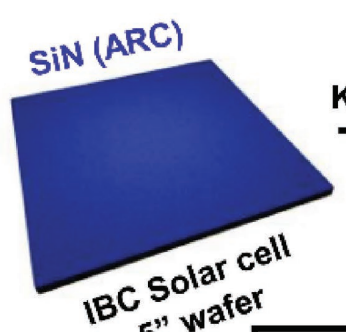

\section{Kapton mask}

PR coating

${ }_{B C}$ Solar ${ }^{c}$ 5" water

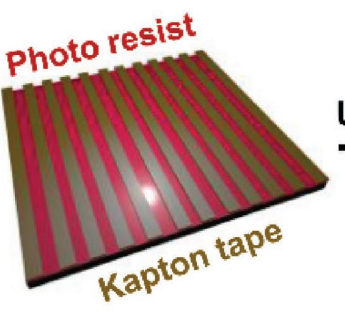

\section{UV exposure}
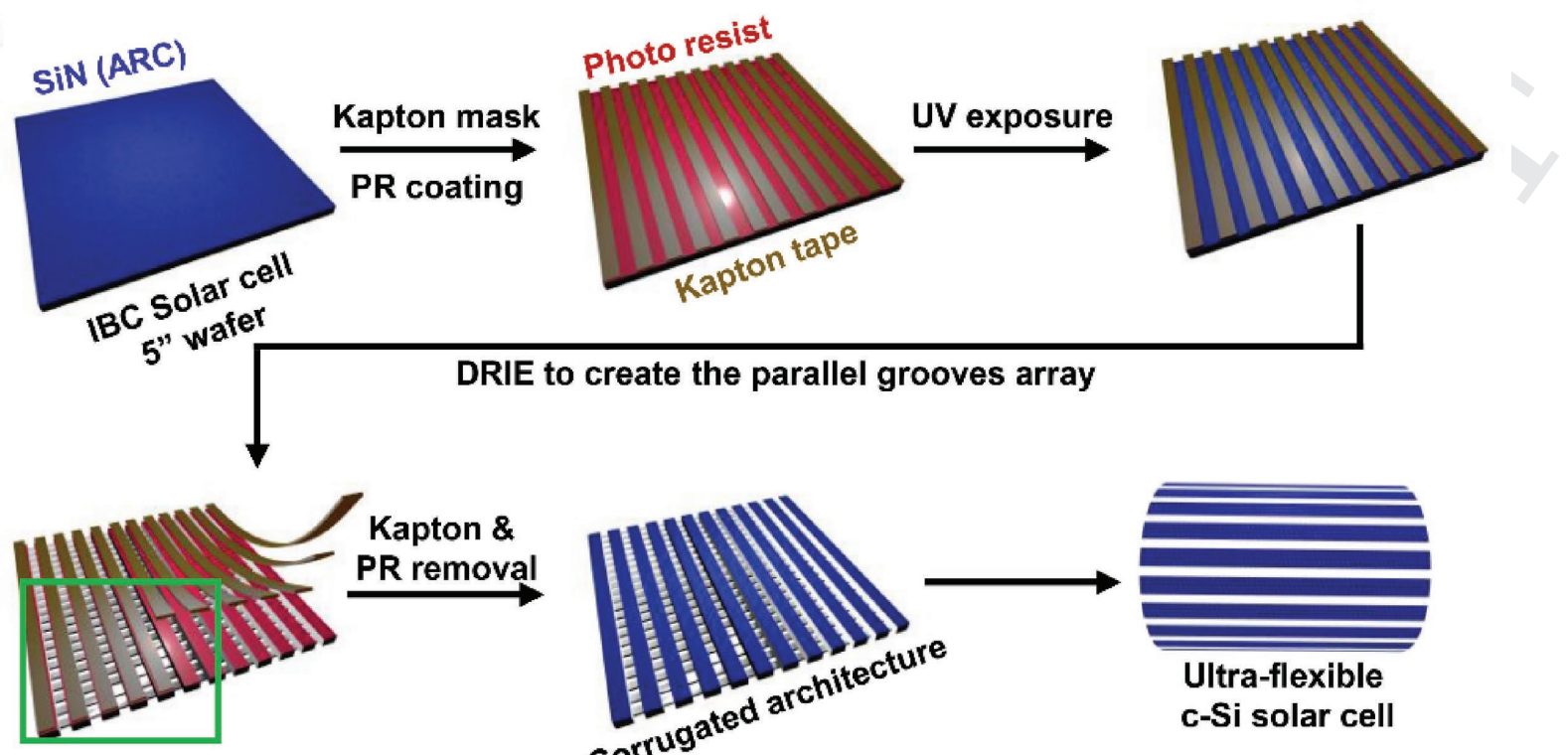

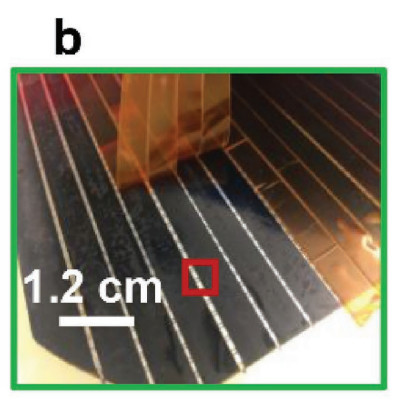

c
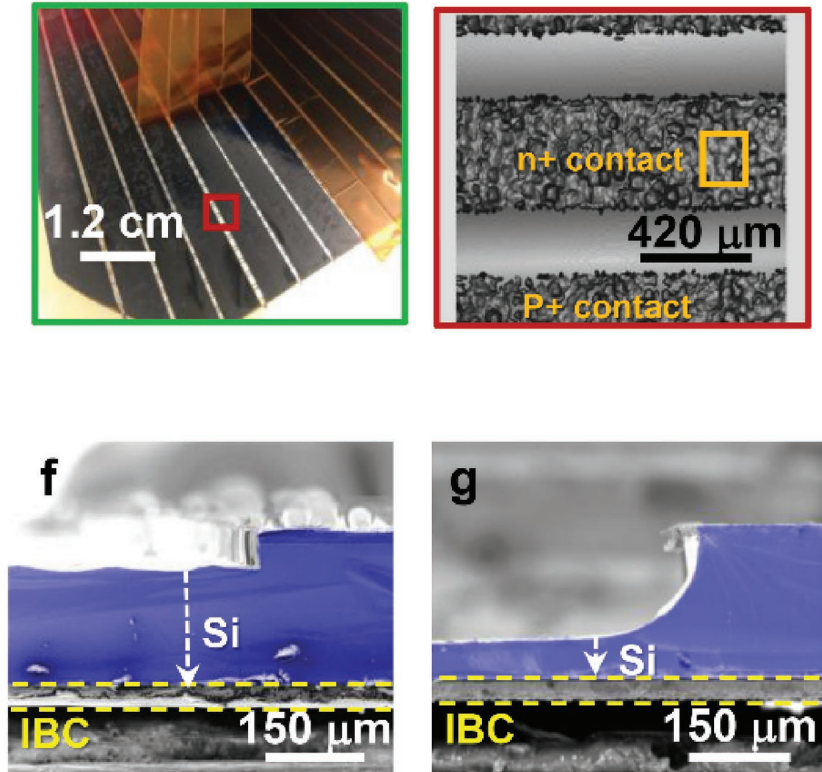

d

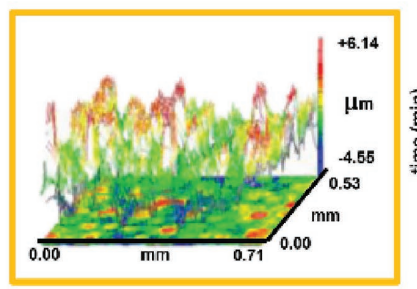

e
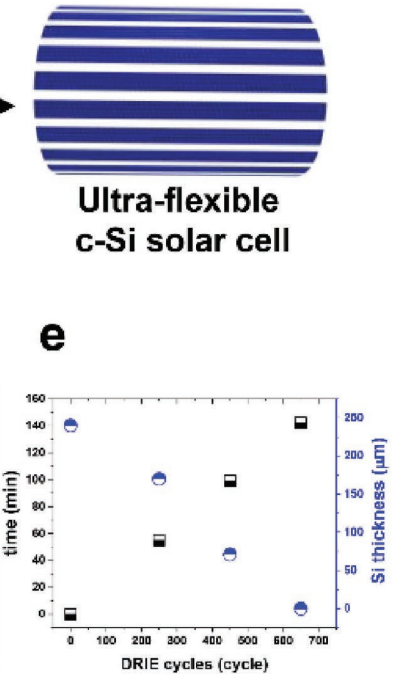

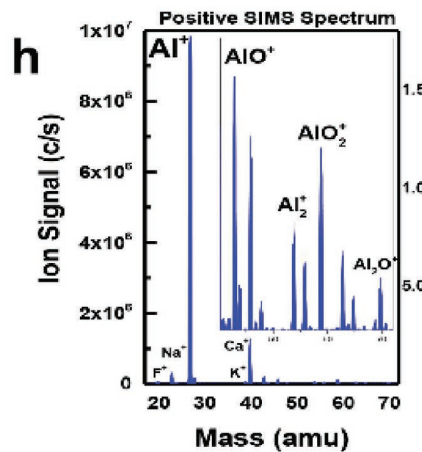

14

15

Figure 2. Progression of the DRIE and corrugation technique process. a) Schematic representation of the corrugation flow. b) Optical images of 45 the $5^{\prime \prime}$ wafer post the DRIE process and during peeling off the Kapton tape. c) Optical microscope image of the IBC upper side after the DRIE. d) Optical profiler measured on the IBC for surface roughness analysis. e) DRIE effect on the silicon thickness at the exposed area (each groove area = $127 \times 0.86 \mathrm{~mm}^{2}$ ). f) and g) Cross-sectional SEM images taken after 250 and 450 etching cycles, respectively. h) SIMS spectra of the IBC post the DRIE in both positive and negative modes.

to be around $16.65 \mathrm{~cm}^{2}$. The $J-V$ characteristics of averaged optimized flexible cells are shown in Figure 3a compared to rigid ones on flat surface where the error is the standard deviation from 10 devices. The $J-V$ and $P-V$ characteristics of the optimized devices are shown in Figure 3a,b, respectively. The open circuit voltage $\left(V_{\text {oc }}\right)=0.620 \pm 0.02 \mathrm{~V}$, short circuit current $\left(U_{\mathrm{sc}}\right)=38.055 \pm 1.2 \mathrm{~mA} \mathrm{~cm}{ }^{-2}$, fill factor $(F F)=72.0139 \pm$ $1.5 \%, \eta=17.017 \pm 0.8 \%$, and $P=17.00 \mathrm{~mW} \mathrm{~cm}^{-2}$ under 1 sun illumination compared to the rigid IBC solar cells which gives the following performance in average: $V_{o c}=0.622 \pm 0.02 \mathrm{~V}, \quad 51$ $J_{\mathrm{sc}}=38.607 \pm 1.2 \mathrm{~mA} \mathrm{~cm}^{-2}, F F=71.9413 \pm 1.5 \%, \eta=17.294 \pm 52$ $0.8 \%$, and $P=17.30 \mathrm{~mW} \mathrm{~cm}^{-2}$ as illustrated in Figure 3c. On 53 the other hand, the total power $(\mathrm{mW})$ which is generated from 54 each flexible cell $\left(15 \times 127 \mathrm{~mm}^{2}\right)$ is reduced with $13.7 \%$ com- 55 pared to the rigid ones as the total power generated from the 56 rigid cell is $328 \mathrm{~mW}$ and reduced to $283 \mathrm{~mW}$ for the flexible 57 corrugated architecture ones as plotted in Figure 3d. This is 58 attributed to the active solar cell loss at the grooves area where 59 
a
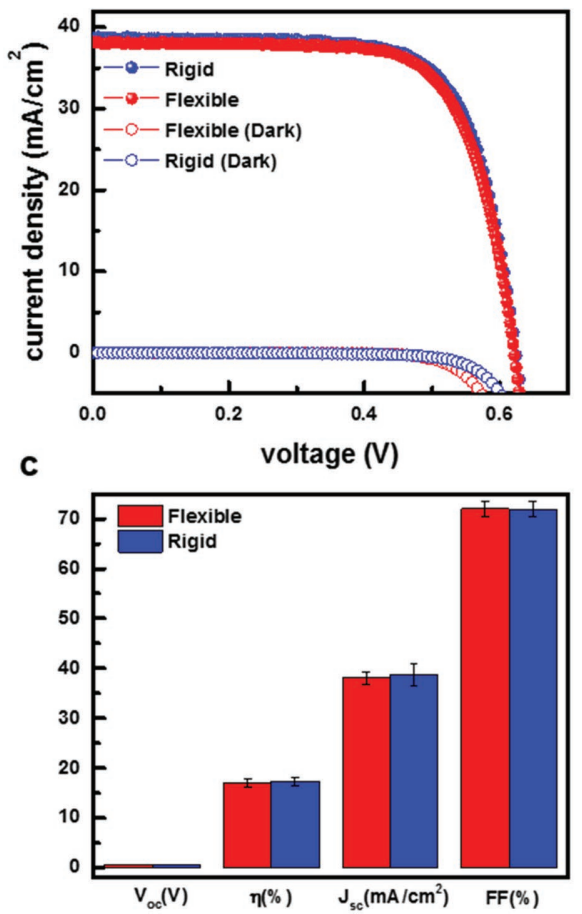

b
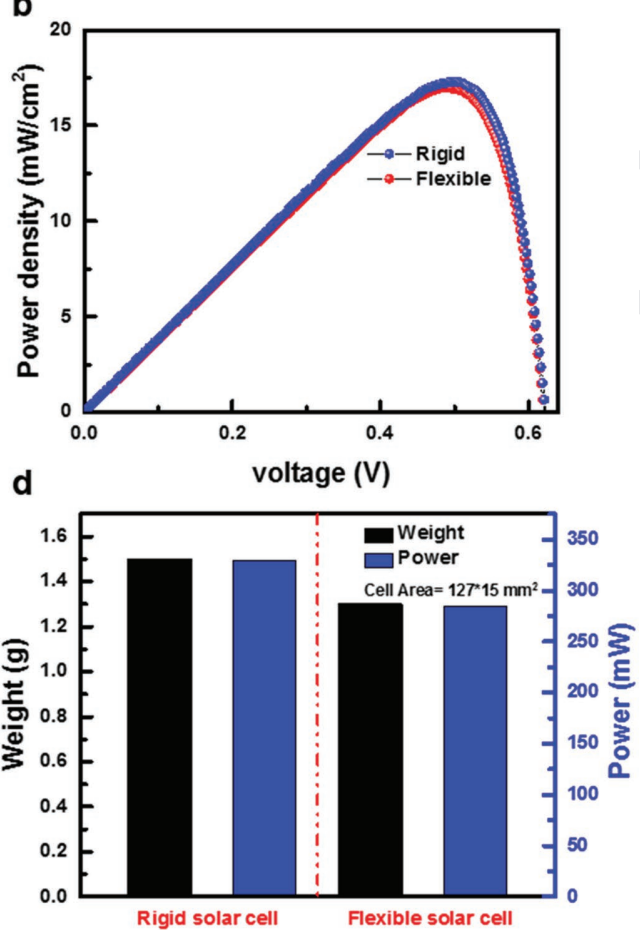

1

2

Figure 3. Electrical performance of the flexible c-Si solar cells compared to the rigid ones. a) J-V performance of the flexible cells enabled via the corrugation technique compared to the rigid devices under solar simulator illumination (1 sun) at the room temperature. b) Power density ( $\mathrm{mW} \mathrm{cm}^{-2}$ ) compression. c) Electrical characteristics comparisons of: open circuit voltage $\left(V_{\text {oc }}\right)$, efficiency $(\eta)$, short circuit current $\left(U_{\text {sc }}\right)$, and FF. d) Weight and total power $(\mathrm{mW})$ measured of devices of an area $=127 \times 15 \mathrm{~mm}^{2}$. Note that all the $J-V$ characteristics measured when the devices are flat.

total weight loss is $13.3 \%$ of each cell as the rigid cells weight is reduced from $1.5 \mathrm{~g}$ into $1.3 \mathrm{~g}$ for the flexible cells. Figure S4a,b (Supporting Information) shows the optical photos of the individual subcells $\left(15 \times 127 \mathrm{~mm}^{2}\right)$ : (a) rigid and (b) corrugated architecture. Comparison of the weight of the rigid and flexible 5 " wafer is shown in Figure S4c (Supporting Information).

\subsection{Mechanical Flexibility of Interdigitated Back Contact}

Our corrugation design consists of several active solar cell segments connected through the IBC (screen printed aluminum) which serves the purpose of the carrier substrate. The segmentation approach has been used recently to obtain flexibility and stretchability even with brittle materials as $\mathrm{Si}$ (fracture strains $<1 \%$ ) as the stretchable electronics is attracting tremendous attentions. ${ }^{[19,20]}$ In our lithography less corrugated approach, the interconnects (grooves) width are $\approx 0.86 \mathrm{~mm}$. To obtain the minimum bending radius for the interconnect, we assume that its length $(\mathrm{L})$ is the perimeter of a circle with radius $\left(R_{\text {bending }}\right)$

$R_{\text {bending }}=\frac{L}{2 \pi}$

Hence, $R_{\text {bending }}$ is $137 \mu \mathrm{m}$, which is consistent with the experimental value obtained via folding the solar cell as SEM image reveals in Figure 11. As the device is bent with the previous bending radii, its fundamental strain $(\varepsilon)$ can be estimated from

$\varepsilon_{\text {max }}=\frac{t}{2 R_{\text {bending }}}$ where $t$ is the interconnects thickness $(\approx 25 \mathrm{um})$ and $\varepsilon_{\max }$ is 31 the maximum stain. Hence, the obtained strain is below $10 \% \quad 32$ which remains below the rupture strain of the screen printed 33 metals that is $>20 \% .{ }^{[21,22]}$ Comparative simulation study is car- 34 ried out with COMSOL for the maximum stain in the intercon- 35 nects as a function of bending angles $(\theta)$ which is defined by 36 the angle between the active solar cells segment during bending 37 and the neutral axis as shown in Figure $4 a-c$. In Figure $4 a$, the 38 maximum strain is below $8 \%$ in the interconnects even with 39 the maximum bending angle is equal to $180^{\circ}$ when both of the 40 active solar cells are folded (see Figure S5, Supporting Informa- 41 tion for detailed 3D modeling).

For further enhancement and future work, the lowest esti- 43 mated bending radius which can be achieved without exceeding 44 $20 \%$ of the interconnects stain would be $62.5 \mu \mathrm{m}$ with a the 45 length of $393 \mu \mathrm{m}$ as designed using the Equations (1) and (2). 46 In Figures S6 and S7 (Supporting Information), the flexible 47 solar cells show little hysteresis in $J_{\mathrm{sc}}$ as the bending radius 48 decreases with light illumination for both of the concave and 49 convex bending. However, both of the $F F$ and $V_{\text {oc }}$ remains in 50 the average value of $72 \%$ and $0.62 \mathrm{~V}$, respectively. We consider 51 that the reduction of the $J_{\mathrm{sc}}$ is due to the variation of the pro- 52 jected area of the bent cells. Given the length of the solar cells 53 $L_{0}$ in its flat state $(11.3 \mathrm{~cm})$, the projected area $S$ of the rectan- 54 gular device under light illumination is

$S=S_{0} \frac{\operatorname{Sin}\left(L_{0} / 2 R_{\mathrm{ca}} \cap\right.}{L_{0} / 2 R_{\mathrm{ca}} \Omega}$ 
a

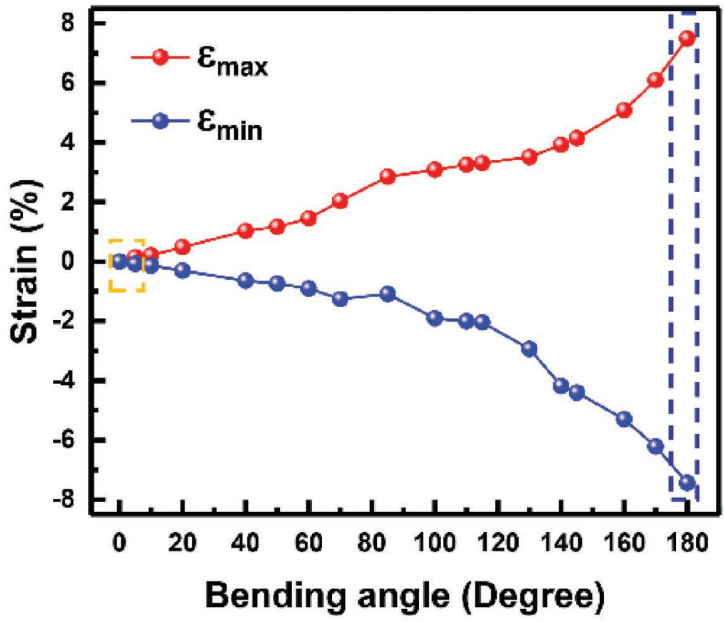

b

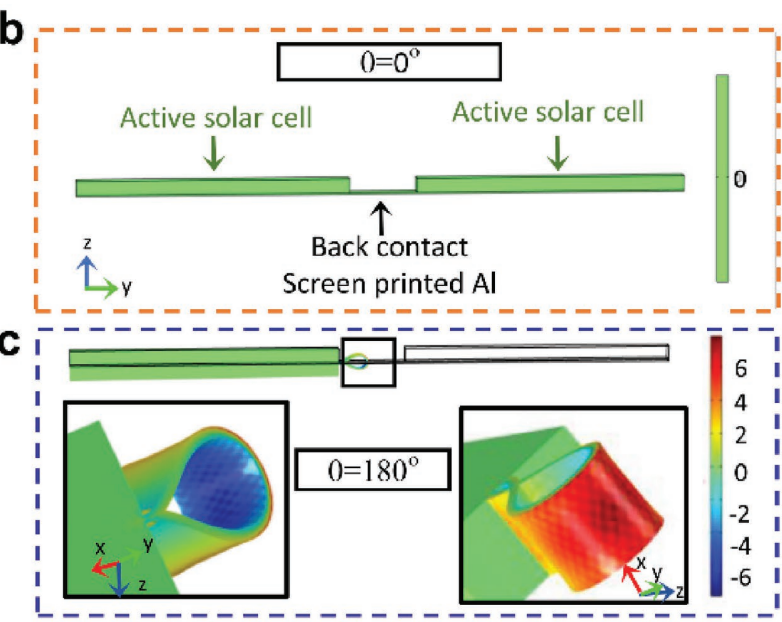

f

e
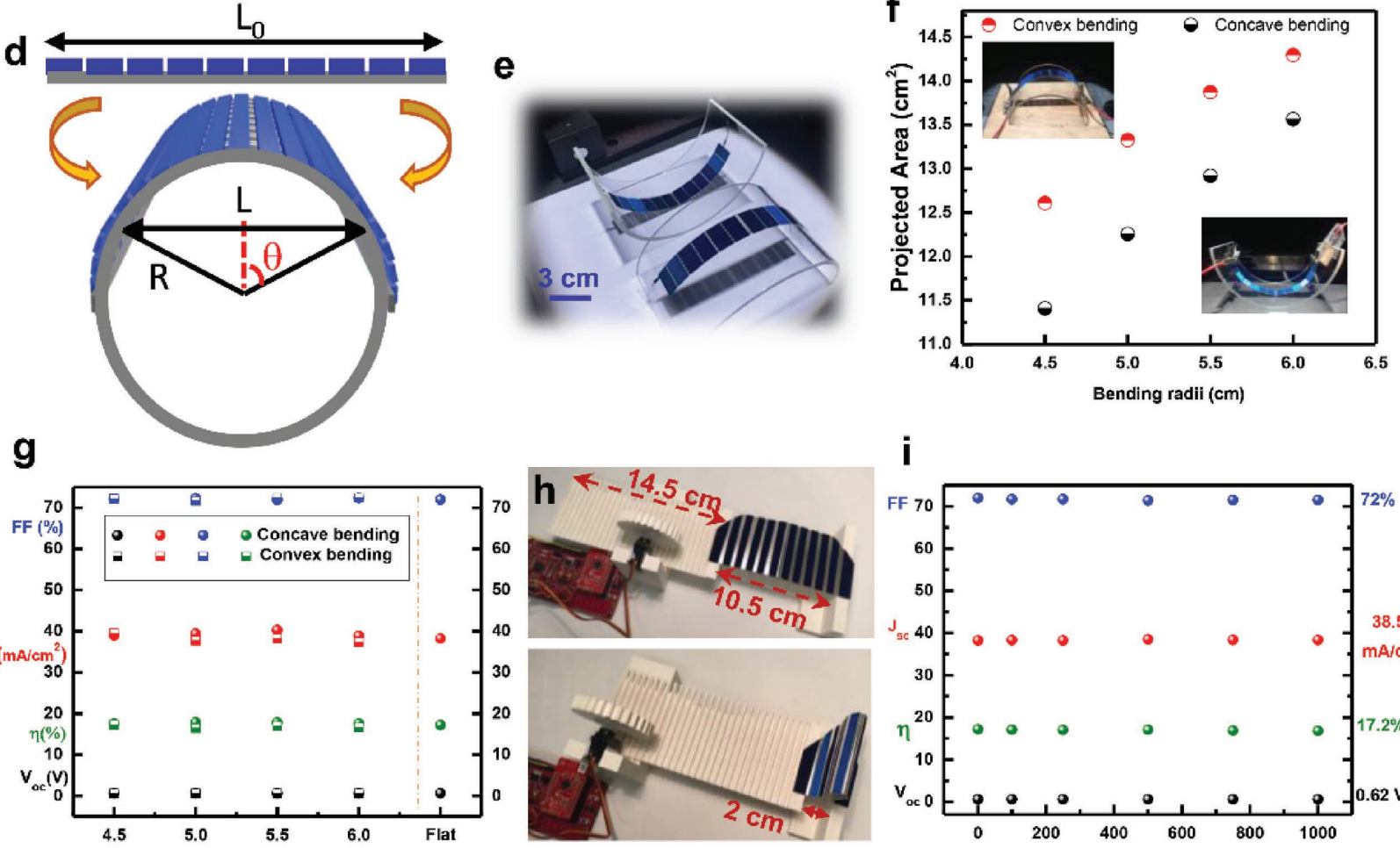

i

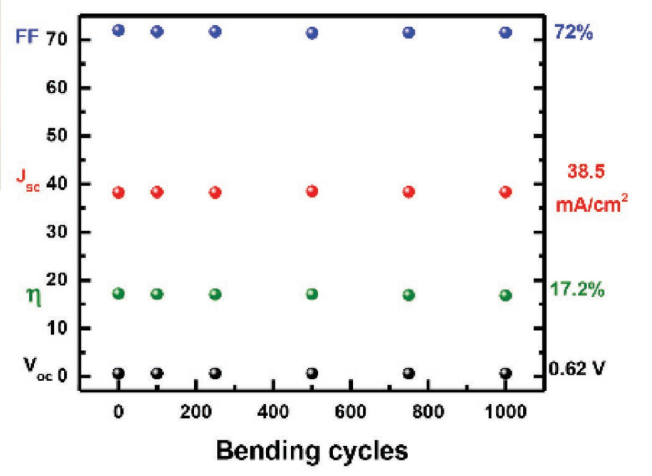

1

2

3

4

5

6

7

8

9

10

11

12

13

14

15

16

17

18

19

20

21

22

23

24

25

26

27

28

29

30

31

32

33

34

35

36

37

38

39

40

41

42

43

44

45

46

47

Figure 4. Extreme mechanical flexibility: 3D strain modeling of the IBC (width $=1 \mathrm{~mm}$ and $25 \mu \mathrm{m}$ thickness) located between silicon solar cells
with thickness of $250 \mu \mathrm{m}$ during bending with different angles $(\theta)$. a) The maximum and minimum strain of IBC as a function of the bending angle. b) and c) Strain compression of $\theta=0$ and $180^{\circ}$, respectively. d) Schematic representation of projected area key components. e) Optical photo of the flexible cells installed on concave and convex glass curvatures $\left(R_{\text {bending }}=6 \mathrm{~cm}\right)$. f) Projected area as a function of the bending radii. The scatter points are calculated with Equations (3) and (4). g) Electrical characteristics of the devices using concave and convex bending compared to the flat devices. h) Optical image of the 3D printed cyclic bending apparatus in both cases: prebent (top) and after bending (bottom). i) Electrical characteristics of the devices as a function of the bending cycles.
$\Omega$ $S_{0}$ is the the co: solar cell when it's flat $\left(16.65 \mathrm{~cm}^{2}\right)$, Figure $4 \mathrm{~d}$. On the other hand, the con curvature bending radius $(A \otimes$ of the same glass curvature is smaller than (5) due to the glass thickness $(\approx 3.6 \mathrm{~mm})$. Therefore, an approximation of $R_{\text {cave }}$ is expressed as P in the radius as illustrated in
$R_{\text {cave }}=R_{\text {vex }}-2 \times t$

where $t$ is the thickness of the glass. Figure 4e shows the 56 optical image of both of the bent cells using convex and con- 57 cave glass curvatures. Figure $4 \mathrm{f}$ displays the projected area 58 associated with the bending radius of $6,5.5,5$, and $4.4 \mathrm{~cm}$ for 59 
the convex and concave bending. Figure $4 \mathrm{~g}$ demonstrates the electrical characterization of a flexible cells with an excellent bending durability after considering the projected area in the $J_{\mathrm{sc}}$ calculations which eliminates any hysteresis and confirms that the projected area is the one key factor of changing of the flexible device performance. ${ }^{[23]}$ In addition, the performance of the zigzag model is measured under illumination as a function of the interior angles of the zigzag without taking in consideration the projection area variation in Figures S7b,c,d (Supporting Information).

The flexible cells are bent for 100, 250, 500, 750, and 1000 cycles to investigate the durability under repeated cyclic bending. Figure $4 \mathrm{~h}$ displays the optical images of the $3 \mathrm{D}$ printed test apparatus in both cases: prebent (top) and after bending (bottom). The electrical characterization of the cells under illumination versus the bending cycles are shown in Figure 4i. It showed a robust performance of the cells without any gradual decrease in the output characteristics.

\subsection{Flexible $L$ Matrix and System on Chip Integrated with the Flexible c-ST Solar Cells Using Indoor Illumination}

The integration of a system consists of five flexible solar cells (each cell area $\approx 127 \times 15 \mathrm{~mm}^{2}$ ) connected in series is demonstrated to explore a seamless integration of the developed corrugation cells using indoor illumination. The integra- 1 tion is explored with both of LEDs matrix and a paper based 2 humidity sensor while the flexible cells are installed on convex 3 curvatures.

Figure 5a displays the output voltage (3-2.9 V) of the five cells 5 connected in series using two (light bulb) office lamps installed 6 on convex bending glass substrate $(R=6 \mathrm{~cm})$. Figure $5 \mathrm{~b}$ pre- 7 sents the system connected to $8 \times 8$ LEDs matrix displaying 8 KAUST logo using (blue, yellow, green, and red) LEDs (addi- 9 tional display of the LEDs matrix using the flexible solar cells 10 can be seen in the Video S1, Supporting Information). Further- 11 more, the cells connected in series are installed on a glass mug 12 used to supply power to a fully functional system as shown in 13 the optical image in Figure 5c. We interfaced a paper based 14 humidity sensor ${ }^{[24,25]}$ with Cypress's Bluetooth Low Energy 15 (BLE) PSoC 4 BLE system-on-chip (SoC) (see Experimental 16 Section for details). The system was then placed on a leaf of a 17 plant and subjected to humid conditions by blowing air from 18 the mouth on the sensors via a pipette. The humidity sensor 19 changes capacitance based upon the relative humidity of the 20 environment. PSOC's Current Digital to Convertor (IDAC) was 21 used to find the capacitance changes of the humidity sensor. 22 For the purpose of demonstration, we only show the detec- 23 tion of a humid condition both with a red LED on the flexible 24 board and notification on the smartphone (as can be seen in 25 the Video S2, Supporting Information). Figure 5d illustrates 26 a

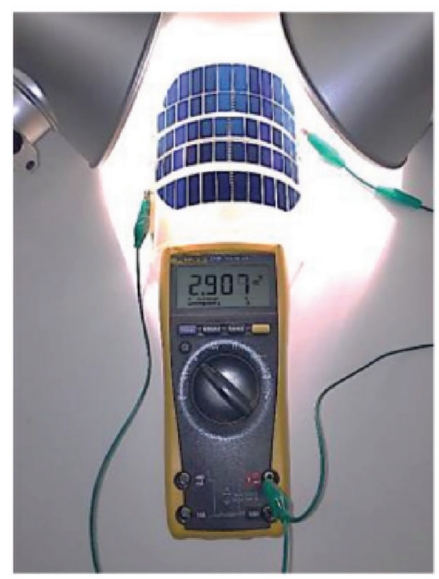

d

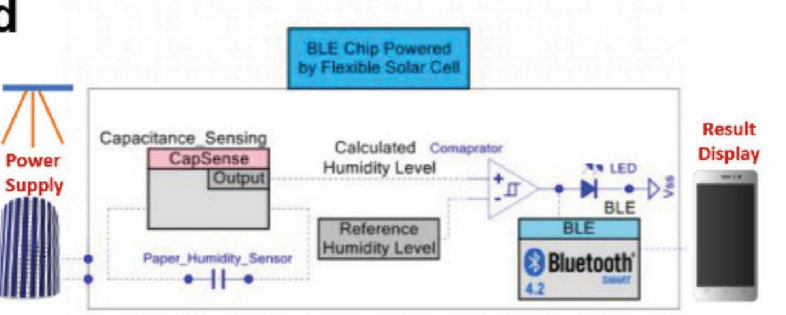

b
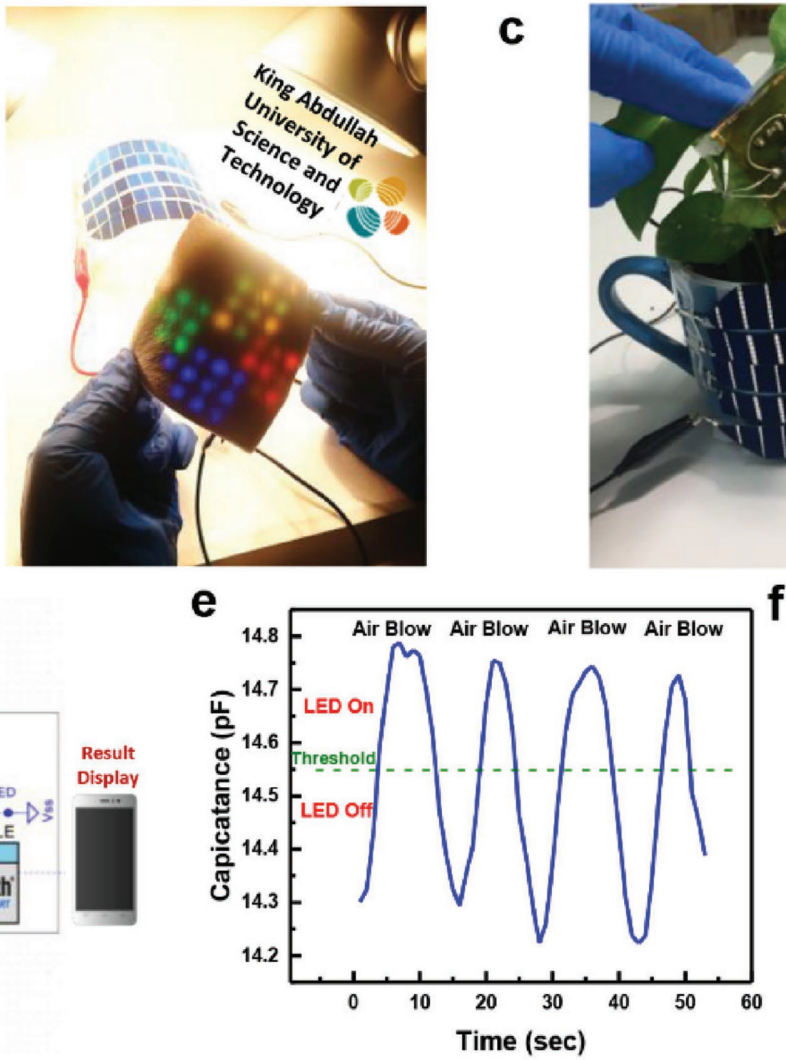

C
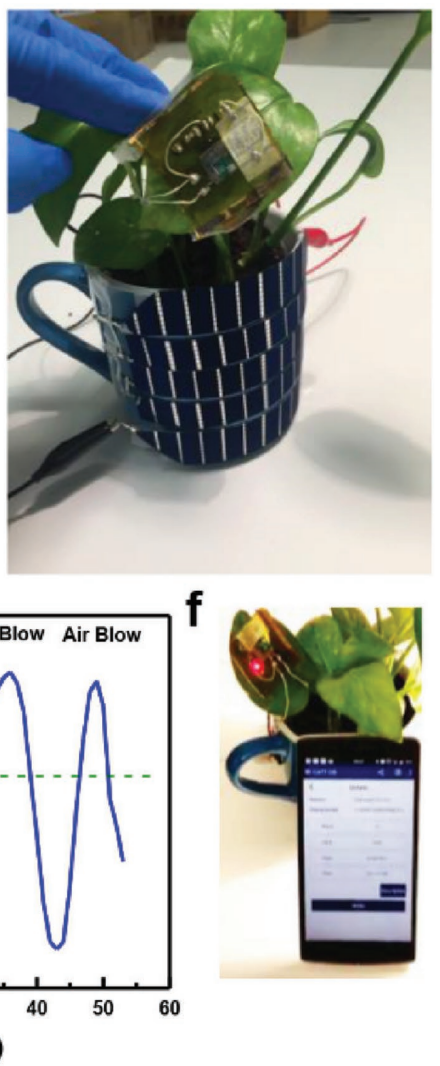

Figure 5. Integration of the corrugated c-Si solar cells. Five cells are connected in series and installed on convex glass curvature. Optical images of: a) output voltage using two bulb lights. b) KAUST logo display using LEDs matrix powered by the flexible solar cells via a desk light. c) Flexible cells are installed on a glass mug used to supply power to a fully functional system placed on a plant leaf and subjected to a humid condition. d) Circuit diagram. e) Humidity sensor response. f) Red LED on a flexible board with notification of the smartphone upon the humidity sensor response. 
1 the full circuit diagram. When the sensor sensed humidity, 2 its capacitance changes which is recorded by IDAC in PSOC 3 as demonstrated in Figure 5e. PSOC then turns on the LED 4 and sends notification to a smartphone as shown in Figure $5 f$. 5 Finally, our achieved efficiency using the measured area of the 6 flexible c-Si solar cells is compared with the data literature in 7 Figure S8 (Supporting Information). ${ }^{[14,17,26-31]}$

\section{Conclusion}

In conclusion, corrugation architecture enabled ultraflexible, high performance c-Si solar cells were demonstrated on a 5 inch wafer via a lithography less complementary metal oxide semiconductorcompatible technique. The flexible cells have the power conversion efficiency of $17.2 \%$ which is comparable to the rigid IBC module efficiency. The corrugation approach consists of active solar cells array (each cell area $\approx 127 \times 6.2 \mathrm{~mm}^{2}$ ) and array of grooves (each groove area $=127 \times \approx 0.86 \mathrm{~mm}^{2}$ ) while the active solar cells are connected via IBC screen printed aluminum which plays the key role as the carrier for the solar cells segments. The screen printed metals can withstand high strain exceeds 20 Moreover, a bending radius of the back contacts lower than $140 \mu \mathrm{m}$ can be achieved with the groove width of $0.86 \mathrm{~mm}$. Hence, the flexible cells showed a consistent electrical performance for the convex and concave bending after the projection area calculations are taken in consideration. Furthermore, the whole 5 inch wafer can be deformed in zigzag and a bifacial module. Moreover, the flexible cells show a high mechanical stability over 1000 cyclic bending. We have demonstrated the integration of the several flexible cells in series with a flexible LEDs matrix and full functional system using indoor illumination. Our corrugation flexible solar cells can broaden the application spectrum and may lead toward unconventional areas of applications.

\section{Experimental Section}

Corrugation Architecture Technique: This technique was applied on 5" industrial supplied ion implanted monocrystalline n-type silicon solar cells with IBC configuration. First, positive PR 9260 was spun on the front side at $2400 \mathrm{r} . \mathrm{m} \quad 60 \mathrm{~s}$. Pyrolysis bake was then carried out at $110^{\circ} \mathrm{C}$ for $180 \mathrm{~s}$. The previous step used on the backside yielding $10 \mu \mathrm{m}$ thick PR on both faces. After that double layer of Kapotin ( $1 / 4^{\prime \prime}$ polyimide film with silicon adhesive) tape was applied in perpendicular lines (15 lines) across the wafer with $\approx 1 \mathrm{~mm}$ gap between the tapes and with wider tapes located at the wafer edges $(\approx 0.9 \mathrm{~mm})$ to prevent thinning the silicon located on top of the IBC common electrodes. The wafer was exposed to broadband stepper at $1.800 \mathrm{~mJ} \mathrm{~cm} \mathrm{c}^{-2}$ followed by development using AZ $726 \mathrm{MIF}$ for $6 \mathrm{~min}$. DRIE step was executed on the top side including SiN (AC) layer and where the whole silicon was etched using Bosch proces f successive deposition and etching cycles $\left(\approx 650\right.$ cycles) using cryogenic cooling at $-20{ }^{\circ} \mathrm{C}$ for smooth sidewalls. The initial Ar plasma strike was performed $10 \mathrm{sccm}$ $20 \mathrm{sccm} \mathrm{SF}_{6}$, and $50 \mathrm{sccm}$ Ar at $15 \mathrm{mTorr}, 2000 \mathrm{~W} \&$ and $20 \mathrm{~W}$ E. $10 \mathrm{~s}$. Principal etching of Si surface takes the following reaction

The deposition step was composed of $100 \mathrm{sccm}$ C4F8 and $5 \mathrm{sccm}$ SF6 at 30 mTorr, $1300 \mathrm{~W} \mathrm{ICP}$, and $5 \mathrm{~W} \mathrm{RF}$ for $3 \mathrm{~s}$ and the etching step was composed of $5 \mathrm{sccm}$ C4F8 and $100 \mathrm{sccm}$ SF6 at 30 mTorr, $1300 \mathrm{~W}$ $\mathrm{ICP}$, and $35 \mathrm{~W}$ RF for $8 \mathrm{~s}$. Plasma polymerization reaction is

$\mathrm{C}_{4} \mathrm{~F}_{8}+e^{-} \rightarrow 2 \mathrm{C}_{2} \mathrm{~F}_{4} \rightarrow \mathrm{CF}_{2} \rightarrow \mathrm{CF}_{3}$

$\mathrm{C}_{2} \mathrm{~F}_{4}, \mathrm{CF}_{2} \rightarrow(\mathrm{CF})_{x}$

Finally, Kanton tape was peeled out and the wafer was cleaned using acetone and A pr PR removal.

Material murestigation: The mass spectra were recorded on interconnects post the DRIE process using dynamic SIMS instrument from Hiden Analytical company (Warrington-UK) operated under ultrahigh vacuum conditions, typically $10^{-9}$ Torr. A continuous $\mathrm{O}_{2}{ }^{+}$ beam of $2 \mathrm{keV}$ energy was employed to sputter the surface while the selected ions were sequentially collected using an MAXIM spectrometer equipped with a quadrupole analyzer.

The Laser-Based Dicing Method: To dice the solar cells into area of $127 \times 15 \mathrm{~mm}^{2}$, we used $1.06 \mu \mathrm{m}$ ytterbium-doped fiber laser (PLS6MW Multi-Wavelength Laser Platform, Universal Laser Systems, USA). The laser interacting with the material strongly depended upon the wavelength, speed, power level of the laser, and the absorption characteristic of the material. The calibration of the laser dicing parameters was carried out to obtain sufficient beam penetration through the entire thickness $(260 \mu \mathrm{m})$ of the device as shown in Figure S3, Supporting Information. Based on the sharp profile of the laser beam with power with $100 \%$, speed of $60 \%$, and $500 \mathrm{kHz}$ was used for the cells dicing. Finally, we gently cleaved cells by hand.

Device Characterization: The devices were first characterized in the dark and under illumination of a solar simulator (ORIEL AM 1.5 Global Spectrum with $100 \mathrm{~mW} \mathrm{~cm} \mathrm{~cm}^{-2}$ intensity). Prior to each measurement, the intensity of the solar simulator was calibrated with a reference Si solar cell and a readout meter for solar simulator irradiance (Newport). $J-V$ characteristics were recorded using a Keithley 2420-C Source Meter. Glass bending curvatures with radius of $9,6,3$, and $2.5 \mathrm{~cm}$ were used for the electrical bending study. Scanning electron microscopy imaging was used at acceleration voltage of $5 \mathrm{kV}$.

SOC: The BLE module comes with integrated antenna, crystal, and flash/EEPROM. The circuit was printed on a flexible polyimide substrate, followed by bonding of paper sensor and BLE chip on the substrate.

\section{Supporting Information}

Supporting Information is available from the Wiley Online Library or from the author.

\section{Conflict of Interest}

The authors declare no conflict of interest.

\section{Keywords}

[1] S. Bauer, S. Bauer-Gogonea, I. Graz, M. Kaltenbrunner, C. Keplinger, R. Schwödiauer, Adv. Mater. 2014, 26, 149. 
[2] T. F. O'Connor, A. V. Zaretski, S. Savagatrup, A. D. Printz, C. D. Wilkes, M. I. Diaz, E. J. Sawyer, D. J. Lipomi, Sol. Energy Mater. Sol. Cells 2016, 144, 438 .

[3] Y. J. Hung, T. Y. Chuang, C. L. Chun, M. S. Cai, H. W. Su, S. L. Lee, IEEE Trans. Electron Devices 2014, 61, 4019.

[4] Z. Gao, C. Bumgardner, N. Song, Y. Zhang, J. Li, X. Li, Nat. Commun. 2016, 7, 11586

[5] J. W. Lee, R. Xu, S. Lee, K.-I. Jang, Y. Yang, A. Banks, K. J. Yu, J. Kim, S. Xu, S. Ma, S. W. Jang, P. Won, Y. Li, B. H. Kim, J. Y. Choe, S. Huh, Y. H. Kwon, Y. Huang, U. Paik, J. A. Rogers, Proc. Natl. Acad. Sci. USA 2016, 113, 6131.

[6] A. T. Kutbee, M. T. Ghoneim, S. M. Ahmad, M. M. Hussain, IEEE Trans. Nanotechnol. 2016, 15, 402.

[ A. T. Kutbee, R. R. Bahabry, K. Alamoudi, M. Ghoneim, M. Cordero, Almuslem, A. Gumus, E. Diallo, J. Nassar, A. Hussain, N. khashab, M. M. Hussain, npj Flexible Electron. 2017, in press.

[8] X. He, Y. Zi, H. Guo, H. Zheng, Y. Xi, C. Wu, J. Wang, W. Zhang, C. Lu, Z. L. Wang, Adv. Funct. Mater. 2017, 27, 1604378.

[9] G.-T. Hwang, J. Yang, S. H. Yang, H.-Y. Lee, M. Lee, D. Y. Park, J. H. Han, S. J. Lee, C. K. Jeong, J. Kim, K.-I. Park, K. J. Lee, Adv. Energy Mater. 2015, 5, 1500051.

[10] D. J. Lipomi, Z. Bao, Energy Environ. Sci. 2011, 4, 3314.

[11] C. Battaglia, A. Cuevas, S. De Wolf, Energy Environ. Sci. 2016, 9, 1552.

[12] C. H. Lee, D. R. Kim, X. Zheng, ACS Nano 2014, 8, 8746.

[13] Q. Lin, H. Huang, Y. Jing, H. Fu, P. Chang, D. Li, Y. Yao, Z. Fan, J. Mater. Chem. C 2014, 2, 1233.

[14] C.-M. Hsu, C. Battaglia, C. Pahud, Z. Ruan, F.-J. Haug, S. Fan, C. Ballif, Y. Cui, Adv. Energy Mater. 2012, 2, 628.

[15] C. H. Yang, C. Y. Hsueh, D. J. Yeh, C. I. Ho, C. M. Leu, Y. H. Yeh, S. C. Lee, IEEE Electron Device Lett. 2011, 32, 1254.

[16] a) S.-M. Lee, R. Biswas, W. Li, D. Kang, L. Chan, J. Yoon, ACS Nano 2014, 8, 10507; b) A. J. Baca, K. J. Yu, J. Xiao, S. Wang, J. Yoon, J. H. Ryu, D. Stevenson, R. G. Nuzzo, A. A. Rockett, Y. Huang, J. A. Rogers, Energy Environ. Sci. 2010, 3, 208.

[17] J. Yoon, A. J. Baca, S.-I. Park, P. Elvikis, J. B. Geddes, L. Li, R. H. Kim, J. Xiao, S. Wang, T.-H. Kim, M. J. Motala, B. Y. Ahn,
E. B. Duoss, J. A. Lewis, R. G. Nuzzo, P. M. Ferreira, Y. Huang, 1 A. Rockett, J. A. Rogers, Nat. Mater. 2008, 7, 907.

[18] A. Goodrich, P. Hacke, Q. Wang, B. Sopori, R. Margolis, T. L. James, M. Woodhouse, Sol. Energy Mater. Sol. Cells 2013, 114, 110.

[19] A. C. C. Sepulveda, M. S. D. Cordero, A. A. A. Carreño, J. M. Nassar, M. M. Hussain, Appl. Phys. Lett. 2017, 110, 134103.

[20] J. A. Fan, W.-H. Yeo, Y. Su, Y. Hattori, W. Lee, S.-Y. Jung, Y. Zhang, Z. Liu, H. Cheng, L. Falgout, M. Bajema, T. Coleman, D. Gregoire, 7 R. J. Larsen, Y. Huang, J. A. Rogers, Nat. Commun. 2014, 5, 3266.

[21] J. Suikkola, T. Björninen, M. Mosallaei, T. Kankkunen, P. Iso-Ketola, L. Ukkonen, J. Vanhala, M. Mäntysalo, Sci. Rep. 2016, 6, 25784.

[22] S. Thuillier, N. Le Maoût, P. Y. Manach, Int. J. Mater. Form. 2010, 3, 11 223.

[23] Z. Liu, P. You, C. Xie, G. Tang, F. Yan, Nano Energy 2016, 28, 13 151

[24] J. M. Nassar, M. D. Cordero, A. T. Kutbee, M. A. Karimi, 14 G. A. T. Sevilla, A. M. Hussain, A. Shamim, M. M. Hussain, Adv. Mater. Tech. 2016, 1, 1600004

[25] J. M. Nassar, K. Mishra, K. Lau, A. A. Aguirre-Pablo, M. M. Hussain, Adv. Mater. Technol. 2017, 2, 1600228.

[26] R. B. Bergmann, C. Berge, T. J. Rinke, J. Schmidt, J. H. Werner, Sol. Energy Mater. Sol. Cells 2002, 74, 213.

[27] S. Saha, M. M. Hilali, E. U. Onyegam, D. Sarkar, D. Jawarani, 21 R. A. Rao, L. Mathew, R. S. Smith, D. Xu, U. K. Das, B. Sopori, 22 S. K. Banerjee, Appl. Phys. Lett. 2013, 102, 163904.

[28] J. L. Cruz-Campa, M. Okandan, P. J. Resnick, P. Clews, T. Pluym, 24 R. K. Grubbs, V. P. Gupta, D. Zubia, G. N. Nielson, Sol. Energy 24 Mater. Sol. Cells 2011, 95, 551.

Q. Yamamoto, M. Yoshimi, T. Suzuki, Y. Tawada, Y. Okamoto, A. Nakajima, MRS Proc. 2011, 507.

[30] C. H. Lee, D. R. Kim, I. S. Cho, N. William, Q. Wang, X. Zheng, Sci. Rep. 2012, 2, 1000

(1) Meier, J. Spitznagel, U. Kroll, C. Bucher, S. Fay, T. Moriarty, Shah, in Proceedings of 3rd World Conference on Photovoltaic Energy Conversion, 2003, Vol. 3, 2003, 2801.

[1] A. Gutiérrez-D., Nano-Scaled Semiconductor Devices: Physics, Modling, Characterisation, and Societal Impact, 2016. 
Query

Q1: Please provide the TOC keyword.

Q2: Please provide the highest academic title (either Dr. or Prof.) for all authors, where applicable.

Q3: The Methods section has been changed to Experimental Section in the sentence 'In order to facilitate....(see Experimental Section for details). Please check.

Q4: Please expand 'LEDs,' 'ICP,' 'RF,' 'IPA,' and 'ARC' at their first occurrences in the text.

Q5: The sentence "The screen printed..exceeds 20" seems incomplete. Please check.

Q6: Please check the unit r.m.p.

Q7: Please check whether all equations have been correctly typeset.

Q8: The equations in Experimental Section have been renumbered from equations 1,2,3,4 to equations 5,6,7,8 in order to make them in sequential order with other equations in the text. Please chek.

Q9: Please provide publication year, volume number and page number in ref. (7).

Q10: Please provide volume no. for ref. (29).

Q11: Please provide publisher and its location in refs. $(31,32)$. 
Reprint Order Form 2017

- please return with your proofs -
Wiley-VCH Verlag, Boschstrasse 12 69469 Weinheim, Germany

Tel.: (+49) 6201606531

Fax: $(+49) 6201606500$

E-mail: advenergymat@wiley-vch.de http://www.advenergymat.de

\section{Manuscript No.}

Please send me and bill me for

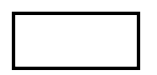
no. of reprints via $\square$ airmail (+ 25 Euro) $\square$ surface mail

high-resolution PDF file (330 Euro).

My e-mail address:

Please note: It is not permitted to present the PDF file on the internet or on company homepages

$\star$ Special Offer $\star$ If you order 200 or more reprints you will get a PDF file for half price.

\section{Information regarding VAT}

Please note that from German sales tax point of view, the charge for Reprints, Issues or Posters is considered as "supply of goods" and therefore, in general, such delivery is a subject to German sales tax. However,this regulation has no impact on customers located outside of the European Union. Deliveries to customers outside the Community are automatically tax-exempt. Deliveries within the Community to institutional customers outside of Germany are exempted from the German tax (VAT) only if the customer provides the supplier with his/her VAT number. The VAT number (value added tax identification number) is a tax registration number used in the countries of the European Union to identify corporate entities doing business there. It starts with a country code (e.g. FR for France, GB for Great Britain) and follows by numbers.

\section{Cover Posters}

Posters are available of all the published covers and frontispieces in two sizes

DIN A2 $42 \times 60 \mathrm{~cm} / 17$ x 24in (one copy: 39 Euro)

DIN A1 60 x 84 cm/ 24 x 33in (one copy: 49 Euro)

Postage for shipping posters overseas by airmail:

+ 25 Euro

Postage for shipping posters within Europe by surface mail: +15 Euro
Mail reprints / cover posters to:

\section{Invoice address:}

\section{Stamp}

VAT no.:

(institutes / companies in EU countries only)

\section{Purchase Order No.:}

\section{Credit Card Payment}

VISA, MasterCard, AMERICAN EXPRESS

Please use the Credit Card Token Generator located at the website below to create a token for secure payment. The token will be used instead of your credit card number.

Credit Card Token Generator:

https://www.wiley-vch.de/editorial production/index.php

Please transfer your token number to the space below.

Credit Card Token Number:

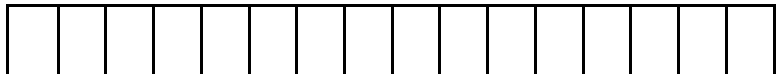

Price list for reprints (The prices include mailing and handling charges. All Wiley-VCH prices are exclusive of VAT)

\begin{tabular}{c|cccccr}
\hline \multirow{2}{*}{ No. of pages } & \multicolumn{5}{c}{ Price (in Euro) for orders of } \\
& 50 copies & 100 copies & 150 copies & 200 copies & 300 copies & 500 copies \\
\hline $1-4$ & 345 & 395 & 425 & 445 & 548 & 752 \\
$5-8$ & 490 & 573 & 608 & 636 & 784 & 1077 \\
$9-12$ & 640 & 739 & 786 & 824 & 1016 & 1396 \\
$13-16$ & 780 & 900 & 958 & 1004 & 1237 & 1701 \\
$17-20$ & 930 & 1070 & 1138 & 1196 & 1489 & 2022 \\
\hline for every additional 4 pages & 147 & 169 & 175 & 188 & 231 & 315 \\
\hline
\end{tabular}

$\star$ Special Offer $\star$ If you order 200 or more reprints you will get a PDF file for half price.

Wiley-VCH Verlag GmbH \& Co. KGaA; Location of the Company: Weinheim;

Chairman of the Supervisory Board: Stephen Michael Smith,

Trade Register: Mannheim, HRB 432833, General Partner: John Wiley \& Sons GmbH, 